\title{
Endovascular repair of the left subclavian artery after gunshot wound: an alternative to surgical treatment
}

\author{
Christophe MARTINEZ ${ }^{1}$, MD; Yamen MAAZOUN ${ }^{1}$, MD; Rodolphe DURIEUX ${ }^{2}$, MD; \\ Jean DEFRAIGNE ${ }^{2} \mathrm{MD}$, PhD; Victor LEGRAND ${ }^{1}, \mathrm{MD}, \mathrm{PhD}$ \\ ${ }^{1}$ Dept. of Cardiology; ${ }^{2}$ Dept. of Cardiovascular Surgery, University Hospital Centre of Liège, Belgium.
}

\begin{abstract}
Penetrating injuries of the subclavian artery are associated with a high morbidity and mortality rate. Endovascular treatment with covered stents (stent grafts) has emerged as an effective alternative to surgery, but this new technique is not exempt from complications. We report the case of a male gunshot victim, treated by a covered stent for haemorrhagic shock due to partial subclavian rupture.
\end{abstract}

Keywords Stent graft-subclavian injury-gunshot-endovascular treatment-haemorrhage.

\section{INTRODUCTION}

Penetrating injuries of the subclavian artery are uncommon, but are often associated with a very high morbidity and mortality rate ${ }^{1}$. Recently, endovascular treatment with placement of stent grafts has emerged as an interesting and effective alternative to surgery ${ }^{2}$. However, this new approach does have some technical limitations and is not exempt from complications. To address this subject, we will report the case of an assault victim treated by percutaneous placement of a stent graft for a gunshot wound to the left subclavian artery. The treatment was carried out in the new, cross-disciplinary medico-surgical unit.
Address for correspondence:

Dr Christophe Martinez, Service de Cardiologie, CHU Sart Tilman, 4000, Liège, Belgium. E-mail: cmartinez@chu.ulg.ac.be

Received 16 May 2012; accepted for publication 28 May 2012.

\section{CLINICAL HISTORY}

A 36-year-old man was brought to our hospital by the Emergency Medical Services (EMS), with a single bullet wound. The bullet had entered through the left pectoral area and exited through the left trapezium. The medical team on duty at the time reported significant external haemorrhage. On admission, the patient was showing signs of haemorrhagic shock, which required sedation, orotracheal intubation and the placement of a central catheter. He was immediately given blood transfusions and a perfusion of macromolecular solution, which stabilised his haemodynamic state (right arm blood pressure 115/85 $\mathrm{mm} \mathrm{Hg}$; heart rate 85 beats/min). The clinical examination revealed no pulse on the left brachial, radial and cubital arteries. An emergency CT scan was performed, with injection of a contrast agent. It revealed a partially ruptured pseudoaneurysm about $4 \mathrm{~cm}$ from the root of the left subclavian artery, persistent active bleeding and a large haematoma in the axillary region. After examining the CT scan, the cardiovascular surgeon, called in to attend to the patient, suggested performing endovascular treatment with the help of the interventional cardiologist. The treatment was carried out in the medico-surgical unit using a retrograde percutaneous approach from the left humeral artery, with 


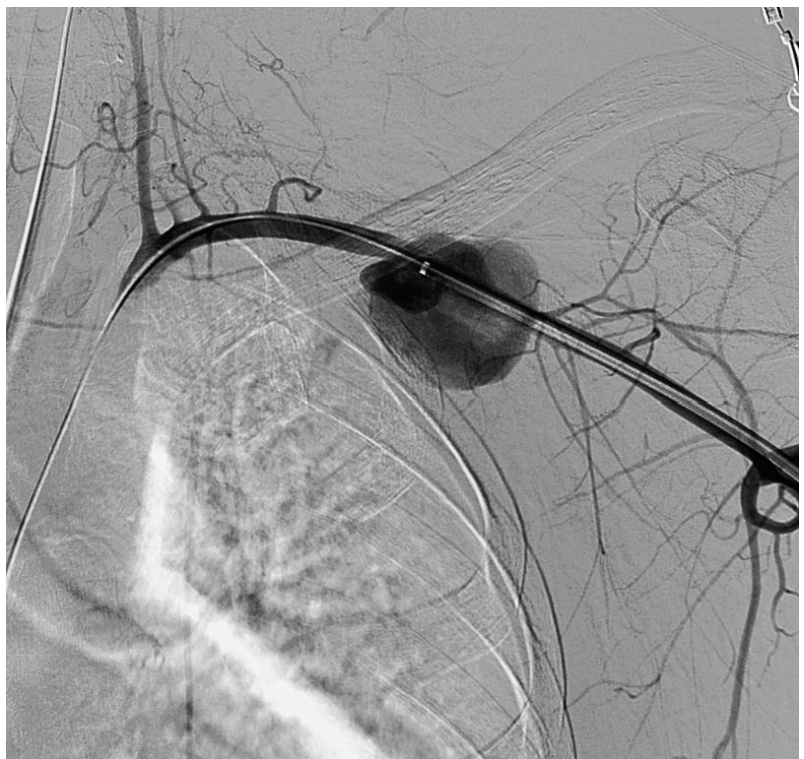

Fig. 1 Selective angiography of the left subclavian artery, showing a partially ruptured aneurysm with extravasation of the contrast agent.

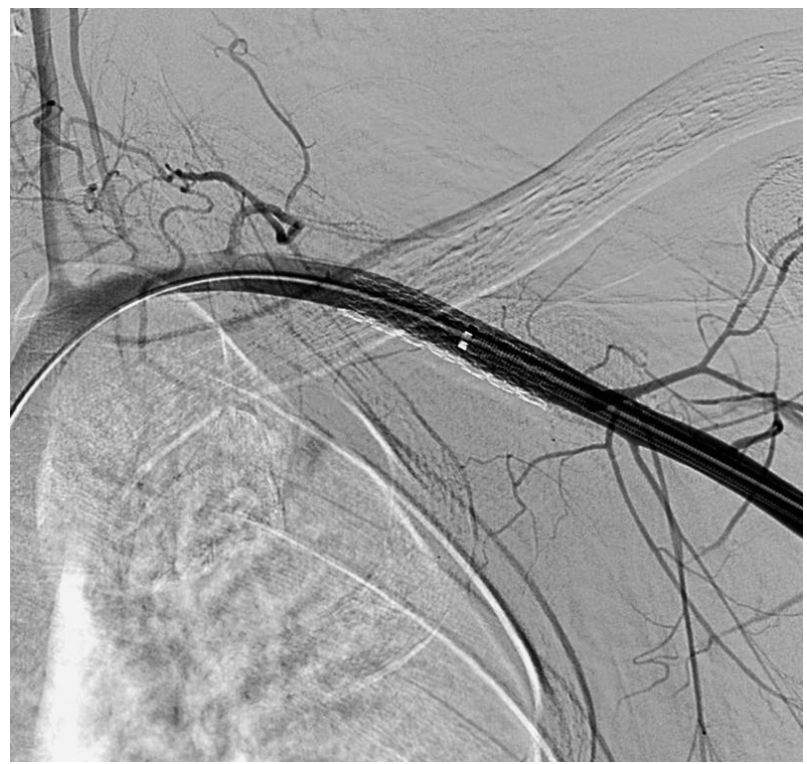

Fig. 3 Final angiography showing optimal deployment of the stent and complete haemostasis.

insertion of a flexible 6-F ( $2 \mathrm{~mm})$ introducer measuring $45 \mathrm{~cm}$ in length. Selective angiography of the subclavian artery confirmed the diagnosis, showing a partially ruptured pseudoaneurysm with active extravasation of the contrast agent (figure 1). After insertion of a hydrophilic guidewire, the arterial lesion was excluded with a balloon-mounted covered stent measuring $6 \mathrm{~mm}$ in diameter and $59 \mathrm{~mm}$ in length (Atrium ${ }^{\circledR} \mathrm{V} 12$, Atrium Medical Corporation) (figure 2). Angiography following deployment showed excellent immediate results: the

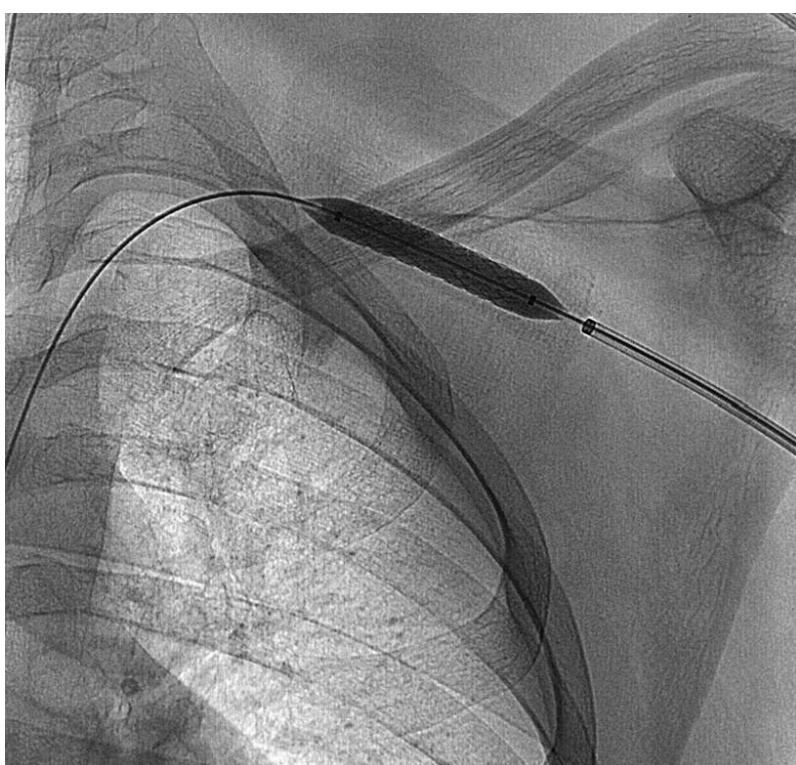

Fig. 2 Placement of the stent graft.

aneurysm was completely excluded and the haemorrhage had stopped altogether (figure 3). The Doppler scan performed before the patient left the catheterisation room, confirmed that the blood flow along the different segments of the left upper limb had been re-established. The patient was then admitted to the Intensive Care Unit, where he was extubated a few hours later. The immediate follow-up care was straightforward and the patient was released from the hospital four days after being admitted, having suffered no complications. He returned for a check-up six weeks later. He was in excellent general health, but complained of disabling claudication of the left hand. A vascular ultrasound scan was performed and confirmed a severe stenosis of the humeral artery upstream of the puncture point. Given the patient's complaints and his young age, corrective surgery was scheduled.

\section{DISCUSSION}

Injuries to the subclavian artery (SA) are uncommon, and are frequently caused by penetrating trauma ${ }^{3,4}$. Such traumas lead to various types of lesion, including arterial wall rupture, intimal tearing, dissection, pseudoaneurysms and/or the development of arteriovenous fistulas. Associated lesions include injuries to the brachial plexus and the aerodigestive tracts ${ }^{3-7}$. Subclavian artery lesions are feared because they are associated with a high morbidity and mortality rate, and because adequate surgical exposure is difficult to obtain. Proximal injuries, the haemostasis of which is a complex process due to 
their intrathoracic location, present the greatest risk ${ }^{3,8}$. Penetrating injuries of the subclavian artery are traditionally treated by standard surgical procedures. This approach is complex and requires the surgeon to make a supraclavicular incision with resection of the clavicle, or to perform a mini-median sternotomy with a supraclavicular extension 9 . Stecco et al. ${ }^{10}$ have reported a postoperative complication rate of $24 \%$. The morbidity and mortality rates vary from $5 \%$ to $40 \%$ depending on the series $^{3,11}$. The factors which increase surgical risk are anatomical deformations caused by large haematomas, severe haemorrhaging prior to clamping and the associated neuro-vascular lesions. The endovascular treatment of subclavian injuries reduces the risk of surgery-induced damage to the surrounding structures, as well as blood $\operatorname{loss}^{7,12}$. A retrospective analysis of several small series of patients shows that mortality and morbidity rates are lower in patients treated by the endovascular approach (5\%) than in patients treated by surgery (10-40\%). However, given the rarity of these incidents, it is not possible to perform a randomised prospective study ${ }^{2}$. Several authors have assessed the feasibility of endovascular treatment and concluded that almost $50 \%$ of subclavian artery injuries could be treated using an endovascular approach $^{7,13}$. Endovascular treatment is appropriate for the following anatomical conditions: intimal lesions, dissections, pseudoaneurysms, arteriovenous fistulas and focal arterial ruptures. The most common contraindications are long segmental injuries, complete transections and the absence of an adequate proximal fixation zone ${ }^{8}$. For some authors, haemodynamic instability is a contraindication for endovascular treatment ${ }^{14}$. For others, on the contrary, patients presenting with partially controlled bleeding can be monitored and stabilised in the catheterisation room as well as in the operating theatre. If endovascular treatment is feasible, it is performed immediately after the diagnostic angiogram. At any time in the procedure, an occlusive balloon can be placed at the proximal end of the subclavian artery to achieve rapid and complete haemostasis, so that the surgeon can operate more easily. Focal injuries that preserve arterial continuity are usually approached by the transfemoral route. The advantages of this route are that it allows for the use of large-calibre sheaths, it provides a straightforward approach to the subclavian artery if the aortic arch is not tortuous, and it presents a low risk of access complications thanks to the use of percutaneous arterial closure devices. The humeral route is preferred for more serious and extensive injuries, as it provides a shorter and easier path for passing the guidewire through the arterial lesion. If the humeral route is used, the stent grafts must be compatible with 6 or 7 -F introducers. The most frequent cause of failure of this procedure is the failure to pass the guidewire through the lesion. If the humeral route is chosen, surgical exposure of the artery may be required given the absence of a pulse and the often severe spasm resulting from the upstream injury. Several types of stent graft have been used in the various series published: balloon-mounted stents or self-expanding stents, covered in either Dacron or PTFE. No significant differences in terms of effectiveness have been reported. The short and medium-term results of endovascular treatment, as reported by Patel et al. ${ }^{15}$, Du Toit et al. ${ }^{6}$ and Hilfiker et al. ${ }^{16}$ are encouraging, as they show a low rate of in-stent restenosis and thrombosis. However, no longterm results have been reported yet. Of course, the durability of endovascular repair has not yet been established and must be better defined. Nevertheless, delayed complications such as in-stent thrombosis or restenosis are not an impediment to subsequent revascularisation ${ }^{17,18}$. At present, there is no general consensus on how to treat traumatic injuries of the subclavian arteries ${ }^{19}$. Better techniques, equipment and imaging solutions, as well as the full-time availability of experienced, specialised and multidisciplinary medical teams, will make it possible to enlarge the indications and to improve the outcome of covered stent (stent graft) treatment.

\section{CONCLUSION}

Our patient's case shows that stent grafts are an interesting alternative to surgery for the acute treatment of penetrating injuries to the subclavian artery, in patients who are haemodynamically stable and require quick intervention to achieve effective haemostasis. This technique reduces morbidity, blood loss, operating times and the risk of nerve injury, and eliminates the need to perform difficult procedures to expose the damaged artery. The indications still need to be properly defined, through comparative studies with longer-term follow-up.

CONFLICTS OF INTEREST: none.

\section{REFERENCES}

1. McKinley AG, Carrim AT, Robbs JV. Management of proximal axillary and subclavian arterial injuries. Br J Surg 2000; 87: 79-85.
2. Cohen JE, Rajz G, Gomori JM, Verstandig A, Berlatzky Y, Anner H, Grigoriadis S, Lylyk P, 
Ceratto R, Klimov A. Urgent endovascular stent-graft placement for traumatic penetrating subclavian artery injuries. J Neurol Sci 2008; 272(1-2): 151-7.

3. Demetriades D, Gomez H, Chahwan S, Charalambides K, Velmahos G, Murray J, Asensio J, Berne TV. Penetrating injuries to the subclavian and axillary vessels. J Am Coll Surg 1999; 188: 290-5.

4. Graham JM, Feliciano DV, Mattox KL, Beall AC Jr, DeBakey ME. Management of subclavian vascular injuries.

J Trauma 1980; 20: 537-44.

5. Hyre CE, Cikrit DF, Lalka SG, Sawchuk AP, Dalsing MC. Aggressive management of vascular injuries of the thoracic outlet. J Vasc Surg 1998; 27: 880-4.

6. du Toit DF, Strauss DC, Blaszczyk M, de Villiers R, Warren BL. Endovascular treatment of penetrating thoracic outlet arterial injuries. Eur J Vasc Endovasc Surg 2000; 19: 489-95.

7. Xenos ES, Freeman M, Stevens S, Cassada D Pacanowski J, Goldman M. Covered stents for injuries of subclavian and axillary arteries. J Vasc Surg 2003; 38: 451-4.

8. Testerman GM, Gonzalez GD, Dale E. CT angiogram and endovascular stent graft for an axillary artery gunshot wound. South Med J 2008; 101: 831-3.

9. Scalea TM, Scalfoni SJ. Angiographically placed balloons for arterial control: a description of a technique. J Trauma 1991; 31: 1671-7.

10. Stecco K, Meier A, Seiver A, Dake M, Zarins C. Endovascular stentgraft placement for treatment of traumatic penetrating subclavian artery injury. J Trauma 2000; 48: 948-50.

11. Yeh MW, Horn JK, Schecter WP, Chuter TA, Lane JS. Endovascular repair of an actively hemorrhaging gunshot injury to the abdominal aorta. J Vasc Surg 2005; 42: 1007-9.

12. White R, Donayre C, Walot I, Kopchok GE, Wilson $\mathrm{E}$, Klein $\mathrm{S}$. Endograft repair of an aortic pseudoaneurysm following gunshot wound injury: impact of imaging on diagnosis and planning of intervention. J Endovasc Surg 1997; 4: 344-51.

13. Filis KA. Endovascular grafting as a complement to open surgery treatment for axillary and subclavian vascular injuries. South Med J 2008; 101: 781-2.

14. Danetz JS, Cassano AD, Stoner MC, Ivatury RR, Levy MM. Feasibility of endovascular repair in penetrating axillosubclavian injuries: a retrospective review.

J Vasc Surg 2005; 41: 246-54.

15. Patel AV, Marin ML, Veith FJ, Kerr A, Sanchez LA. Endovascular graft repair of penetrating subclavian artery injuries. J Endovasc Surg 1996; 3: 382-8.

16. Hilfiker PR, Razavi MK, Kee ST, Sze DY, Semba CP, Dake MD. Stent/graft therapy for subclavian artery aneurysms and fistulas: single-center mid-term results. J Vasc Interv Radiol 2000; 11: 578-84.

17. Feezor RJ, Lee WA. Management of the left subclavian artery during TEVAR. Semin Vasc Surg 2009; 22: 159-64.

18. Cooper DG, Walsh SR, Sadat U, Noorani A, Hayes PD, Boyle JR. Neurological complications after left subclavian artery coverage during thoracic endovascular aortic repair: a systematic review and meta-analysis. J Vasc Surg 2009; 49: 1594-601.

19. Peterson BG, Eskandari MK, Gleason TG Morasch MD. Utility of left subclavian artery revascularization in association with endoluminal repair of acute and chronic thoracic aortic pathology. J Vasc Surg 2006; 43: 433-9. 